\title{
ANTEGRADE COLD BLOOD CARDIOPLEGIA IS NOT DEMONSTRABLY ADVANTAGEOUS OVER COLD CRYSTALLOID CARDIOPLEGIA IN SURGERY FOR CONGENITAL HEART DISEASE
}

J. Nilas Young, MD

Isaac O. Choy, MD

Nolli K. Silva, MD

Derek Y. Obayashi, MA

Howard E. Barkan, DrPH
Objective: The superiority of blood cardioplegia in pediatric cardiac surgery has not previously been challenged in a controlled clinical trial. The purpose of this study was to compare antegrade cold blood versus cold crystalloid cardioplegia in pediatric cardiac surgery. Methods: One hundred thirty-eight pediatric patients (mean age 32 months; $95 \%$ CL 24.2 to 39.8 months; range 1 day to 15 years) were prospectively randomized to receive either cold blood (4:1 dilution, blood/Plegisol, potassium chloride 15 $\mathrm{mEq} / \mathrm{L} ; n=62$ ) or cold crystalloid (Plegisol; $n=76$ ) cardioplegic solution during a variety of operations for congenital heart disease. Multiple doses of cold $\left(4^{\circ} \mathrm{C}\right)$ cardioplegic solution was administered antegradely in addition to topical cooling during ischemic arrest. Myocardial recovery and outcome measures were assessed by five clinical end points: (1) inotropic support, (2) echocardiographic assessment of ventricular function, (3) overall complication rate, (4) length of stay in the intensive care unit, and (5) 30-day survival. Multiple logistic regression and multivariate analysis of variance were used to investigate which of the following clinical determinants were contributory: (1) cardioplegia, (2) urgency of operation, (3) aortic crossclamp time, (4) age, and (5) cyanosis. Population data did not differ between the two cardioplegia groups $(p>0.05)$. Results: The most important clinical determinant of studied end points was the aortic crossclamp time $(p<0.05)$. The type of cardioplegic solution (blood vs crystalloid) was less important ( $p>0.05$ ). The only statistically significant difference between blood and crystalloid cardioplegia for the measured clinical end points was the level of intraoperative inotropic support $(p<$ 0.05 ), although this did not correlate with any significant differences in measured ventricular function. Conclusion: Our results suggest no clear clinical advantage of antegrade cold blood cardioplegia over crystalloid cardioplegia during hypothermic cardioplegic arrest in pediatric cardiac surgery. The aortic crossclamp time was the strongest predictor of measured outcomes. (J Thorac Cardiovasc Surg 1997;114:1002-9)
$B^{1}$ ood cardioplegia has theoretic advantages over crystalloid cardioplegia, namely, improved oxygen delivery, onconicity, buffering capacity, and an-

From the Division of Cardiothoracic Surgery, Children's Hospital, Oakland, Calif.

Read at the Seventy-seventh Annual Meeting of The American Association for Thoracic Surgery, Washington, D.C., May 4-7, 1997.

Received for publication May 12, 1997; revisions requested July 28, 1997; revisions received August 25, 1997; accepted for publication August 26, 1997.

Address for reprints: J. Nilas Young, MD, Center for Cardiac Surgery, 2999 Regent St., Suite 626, Berkeley, CA 94705.

Copyright (C) 1997 by Mosby-Year Book, Inc.

$0022-5223 / 97 \$ 5.00+0 \quad \mathbf{1 2 / 6 / 8 5 6 8 1}$ tioxidant capability. Since its introduction in 1977 , blood cardioplegia has achieved a dominant role relative to crystalloid cardioplegia in adult cardiac surgery. ${ }^{1,2}$ The role and advantages of blood cardioplegia in pediatric cardiac surgery are less well defined. Congenital heart surgeons are divided in regard to their use of blood and crystalloid cardioplegic solutions. ${ }^{3}$ No randomized clinical trial comparing these two cardioplegic agents has been reported in a pediatric scenario. We attempted to better define the role of blood cardioplegia for pediatric patients undergoing cardiac surgery by conducting a prospective randomized controlled clinical trial of antegrade cold blood versus antegrade cold crystalloid cardioplegia. 
Table I. Primary diagnoses and procedures performed for patients entered into the study (September 1994 through December 1995)

\begin{tabular}{llrr}
\hline \multicolumn{1}{c}{ Primary diagnosis } & \multicolumn{1}{c}{ Primary procedure } & $n$ & \% of 138 \\
\hline VSD & VSD repair & 59 & 42.8 \\
TOF* & TOF repair & 18 & 13.0 \\
Single ventricle* & Fontan procedure & 11 & 8.0 \\
AS & AS repair/aortoplasty & 8 & 5.8 \\
CAVC defect & CAVC repair & 8 & 5.8 \\
Conotruncal abnormality with VSD* & Rastelli procedure & 8 & 5.8 \\
TGA \pm VSD* & Arterial switch \pm VSD & 5 & 3.6 \\
TAPVC & TAPVC repair & 5 & 3.6 \\
Complex RVOT/pulm. arterial reconstruction & RVOT reconstruction & 4 & 2.9 \\
Hypoplastic left heart syndrome* & Norwood procedure & 3 & 2.2 \\
DORV* & DORV repair & 2 & 1.4 \\
Aortic valvular insufficiency & Ross procedure & 2 & 1.4 \\
Mitral valvular insufficiency & Mitral valve replacement & 2 & 1.4 \\
Ebstein's anomaly with TGA* & Damus procedure & 1 & 0.7 \\
Subaortic stenosis & Konno procedure & 1 & 0.7 \\
Single ventricle with TGA* & Bidirectional Glenn shunt & 1 & 0.7
\end{tabular}

VSD, Ventricular septal defect; $T O F$, tetralogy of Fallot; $A S$, aortic stenosis; $C A V C$, complete atrioventricular canal; $T G A$, transposition of the great arteries; $T A P V C$, total anomalous pulmonary venous connection; RVOT, right ventricular outflow tract; $D O R V$, double-outlet right ventricle.

*Cyanotic lesions $(n=54)$.

\section{Methods}

Patients. One hundred thirty-eight patients (75 male, 63 female) undergoing a variety of congenital heart operations requiring cardiopulmonary bypass and ischemic cardiac arrest were entered into the study from September 1994 through December 1995. Isolated atrial septal defects (all variants) were prospectively excluded because of the anticipated brief ischemic times. Mean and median patient ages were 32.0 and 12.0 months, respectively ( $95 \%$ confidence limits [CL] 24.2 to 39.8 months; range 1 day to 15 years). Thirty-seven patients $(26.8 \%)$ were younger than 6 months of age. Table I shows the distribution of the primary diagnoses and operations performed. One hundred twenty cases $(87 \%)$ were elective and 18 cases $(13 \%)$ were urgent (operation required within a 48 -hour period). The mean and median ages for patients undergoing urgent operations were 2.4 and 0.5 months, respectively (95\% CL 0.7 to 4.0 months; range 1 day to 10 months). Fifty-four operations ( $39 \%$ ) were for cyanotic lesions. The mean and median ages for patients with cyanotic lesions were 20.8 and 9.0 months, respectively (95\% CL 10.4 to 31.1 months; range 1 day to 14.5 years). Population data did not differ significantly between the blood and crystalloid cardioplegia groups (Table II). Informed consent was obtained from parents of all patients before entry into the study.

Randomization. Patients were prospectively randomized to receive either blood (4:1 dilution, blood/Plegisol, potassium chloride adjusted to $15 \mathrm{mEq} / \mathrm{L}$ ) or crystalloid cardioplegic solution (Plegisol). Approximately 1 hour before the start of the operation, the perfusionist opened a prepackaged envelope containing the randomized cardioplegia assignment. Sixty-two patients $(45 \%)$ received blood cardioplegia and 76 patients $(55 \%)$ received crystalloid cardioplegia. Randomization was not blinded because of the visual characteristics of the cardioplegic solutions. The constituents of the two cardioplegic agents are described in the appendix.

Operative protocol. Cardiopulmonary bypass was instituted at normothermia with a slightly hypocalcemic prime $(0.75$ to $1 \mathrm{mmol} / \mathrm{L})$ and with relatively normoxemic oxygen tensions (oxygen tension $=125$ to $160 \mathrm{~mm} \mathrm{Hg}$ ). Systemic hypothermic perfusion to $30^{\circ} \mathrm{C}$ was achieved in all patients, and then the aorta was crossclamped and antegrade cardioplegia administered. A temperature probe was placed posteriorly in the interventricular septum, and a topical gauze sponge containing ice slush was placed anteriorly over the ventricular mass. Continued systemic cooling to $25^{\circ} \mathrm{C}$ was subsequently achieved in the majority of patients. Patients undergoing complex repairs or patients requiring circulatory arrest periods of more than several minutes underwent further systemic cooling (range $22^{\circ}$ to $16^{\circ} \mathrm{C}$ ) after aortic crossclamping at $30^{\circ} \mathrm{C}$. Forty patients $(29 \%)$ underwent total circulatory arrest (mean and median circulatory arrest times 32.8 and 29.0 minutes, respectively; $95 \%$ CL 24.7 to 48.9 minutes; range 1 to 87 minutes).

Cardioplegic administration was as follows: a $30 \mathrm{ml} / \mathrm{kg}$ dose of cardioplegic solution was initially administered antegradely at $4^{\circ} \mathrm{C}$ with simultaneous monitoring of aortic root pressure. ${ }^{4}$ Delivery of the cardioplegic solution was accomplished over 2 to 4 minutes, and flow was controlled to maintain an aortic root pressure between mean systemic arterial and diastolic pressures. Repeated doses of cardioplegic solution $(15 \mathrm{ml} / \mathrm{kg})$ were administered at 20 to 30-minute intervals depending on the conduct of the operation and maintenance of septal temperature at $15^{\circ} \mathrm{C}$ or less. At the completion of the aortic crossclamp period the heart was filled with blood or saline solution, or both, and vigorously vented for air. On removal of the aortic crossclamp, reperfusion was controlled by gradually increasing cardiopulmonary bypass flow to $25 \%, 50 \%, 75 \%$, 
Table II. Population data for blood versus crystalloid cardioplegia

\begin{tabular}{lccc}
\hline & $\begin{array}{c}\text { Blood: } \\
\text { Mean } \\
(95 \% \text { CL) }\end{array}$ & $\begin{array}{c}\text { Crystalloid: } \\
\text { Mean } \\
(95 \% \text { CL) }\end{array}$ & $\begin{array}{c}p \\
\text { Value }\end{array}$ \\
\hline Age (mo) & $35.6(22.2-46.9)$ & $28.8(19.1-38.4)$ & $0.45^{*}$ \\
$\begin{array}{c}\text { Aortic crossclamp } \\
\text { time (min) }\end{array}$ & $68.8(66.7-77.0)$ & $65.9(58.5-73.3)$ & $0.59^{*}$ \\
$\begin{array}{c}\text { Urgent cases } \\
\quad \text { No. of patients) }\end{array}$ & 7 & 11 & $0.62 \dagger$ \\
$\begin{array}{c}\text { Cyanotic cases } \\
\text { (No. of patients) }\end{array}$ & 30 & 24 & $0.08 \dagger$ \\
\hline
\end{tabular}

$C L$, Confidence limits.

${ }^{*}$ Student's $\mathbf{t}$ test.

$\dagger$ Fisher's exact test.

and $100 \%$ levels at 2 - to 3 -minute intervals. The calcium concentration of the systemic perfusate was corrected to a normal range approximately 15 to 20 minutes after aortic unclamping or just before termination of cardiopulmonary bypass. Ventricular distention during reperfusion and rewarming was avoided by regulation of systemic venous return or by ventricular sumping (or by a combination of these methods). Dopamine ( $5 \mu \mathrm{g} / \mathrm{kg}$ per minute) was routinely administered before discontinuation of cardiopulmonary bypass.

Clinical determinants (independent variables). The following determinants were analyzed as predictors of outcome: (1) cardioplegic solution (blood vs crystalloid), (2) urgency of operation (elective vs urgent), (3) aortic crossclamp time (minutes), (4) age of the patient (months), and (5) cyanosis.

Clinical end points (dependent variables). The following clinical end points were evaluated: (1) ventricular function determined echocardiographically, (2) inotropic dependency, (3) complication rate, (4) length of stay in the intensive care unit (ICU), and (5) 30-day survival. Echocardiographic assessment of global and segmental ventricular function was performed by an echocardiologist and graded on a scale of 1 to $10(1=$ worst, $10=$ best; 5 points maximum each for global and segmental function). Echocardiograms were performed during the operation after weaning from cardiopulmonary bypass (ECHO-OR) and in the first 24 hours after the operation (ECHO-PO). The total dose of inotropic support was calculated during the operation 30 minutes after discontinuation of cardiopulmonary bypass (INT-OR) and at the end of the first 8 hours after the operation (INT-PO). An inotropic dosage score based on relative inotropic potencies was calculated as dopamine + dobutamine + amrinone $+10 \times$ isoproterenol $+100 \times$ epinephrine in micrograms per kilogram per minute. ICU length of stay was truncated at 30 days to minimize the influence of outliers on calculated means and variances.

Statistical analysis. Standard techniques were used to calculate descriptive statistics. Variability was analyzed using confidence limits (CL). Confidence limits for nominal variables were calculated according to the normal approximation to the binomial distribution. Confidence limits for interval variables were calculated by means of
Table III. Results of multiple logistic regression analysis for 30-day hospital mortality and complications

\begin{tabular}{lcccc}
\hline & & \multicolumn{2}{c}{$95 \%$ CL } & $p$ \\
\cline { 3 - 4 } \multicolumn{1}{l}{ Independent variables } & Odds ratio & Lower & Upper & Value \\
\hline Mortality & & & & \\
$\quad$ Cardioplegia & 1.543 & 0.524 & 4.538 & 0.431 \\
Aortic crossclamp time & 1.068 & 1.027 & 1.111 & 0.001 \\
Age & 0.962 & 0.901 & 1.028 & 0.256 \\
Urgency & 0.861 & 0.273 & 2.712 & 0.798 \\
Cyanosis & 1.081 & 0.395 & 2.956 & 0.880 \\
Complications & & & & \\
Cardioplegia & 1.008 & 0.678 & 1.497 & 0.970 \\
Aortic crossclamp time & 1.026 & 1.012 & 1.041 & 0.0004 \\
Age & 1.000 & 0.991 & 1.009 & 0.974 \\
$\quad$ Urgency & 0.779 & 0.433 & 1.403 & 0.406 \\
Cyanosis & 0.786 & 0.509 & 1.214 & 0.277 \\
\hline
\end{tabular}

$C L$, Confidence limits.

the standard error of the mean. Full and partial correlation coefficients were used to calculate the strengths of association between pairs of variables. The statistical significance of associations between pairs of variables was evaluated with the use of $\chi^{2}$ or Fisher's exact test as appropriate (given number of categories and sample size) for nominal variables and Student's $t$ test for intervaldependent variables. The statistical significance of multivariate associations was evaluated by means of multiple logistic regression for binary-dependent variables (e.g., occurrence of any postoperative complication). Confidence intervals around odds ratios calculated in multiple logistic regressions were calculated by means of the Wald statistic, and multivariate analysis of covariance was used to explore the association of cardioplegic agents with interval-dependent variables (i.e., volume of inotropic support, echocardiographic rating of ventricular function, and ICU length of stay) considered individually, while controlling for covariates (i.e., crossclamp time, age, preoperative cyanosis, and agency of the procedure). Statistics were calculated with the use of the computer program SPSS for Windows, version 7.0 (SPSS, Inc., Chicago, Ill.).

\section{Results}

Survival and complications. By multiple logistic regression analysis, aortic crossclamp time (mean 67.2 minutes; median 63.5 minutes; $95 \%$ CL 61.8 to 72.6 minutes; range 9 to 228 minutes) was the only determinant that had a statistically significant association with survival $(p=0.001$; Table III). The mean aortic crossclamp time for survivors was 63.8 minutes (59.0 to 68.6 minutes; $95 \% \mathrm{CL}$ ), compared with a mean crossclamp time for nonsurvivors of 122.3 minutes (81.1 to 163.4 minutes; 95\% CL). Among the eight nonsurvivors, three deaths occurred in patients judged to have adequate repairs but inadequate ventricular function (and possibly 
Table IV. Incidence of mortality and complications for cardioplegia, urgency, and cyanosis

\begin{tabular}{|c|c|c|c|c|}
\hline & \multicolumn{2}{|c|}{ Mortality } & \multicolumn{2}{|c|}{ Complications } \\
\hline & $\begin{array}{l}\text { No. of } \\
\text { patients }\end{array}$ & $\begin{array}{c}\% \text { of } \\
n\end{array}$ & $\begin{array}{l}\text { No. of } \\
\text { patients }\end{array}$ & $\begin{array}{c}\% \text { of } \\
n\end{array}$ \\
\hline \multicolumn{5}{|l|}{ Cardioplegia } \\
\hline $\begin{array}{l}\text { Blood } \\
(n=62)\end{array}$ & 2 & 3.2 & 22 & 35.5 \\
\hline $\begin{array}{l}\text { Crystalloid } \\
(n=76)\end{array}$ & 6 & 7.9 & 25 & 32.9 \\
\hline \multicolumn{5}{|l|}{ Urgency } \\
\hline $\begin{array}{l}\text { Elective } \\
(n=120)\end{array}$ & 6 & 5.0 & 38 & 31.7 \\
\hline $\begin{array}{l}\text { Urgent } \\
(n=18)\end{array}$ & 2 & 11.1 & 9 & 50.0 \\
\hline \multicolumn{5}{|l|}{ Cyanosis } \\
\hline $\begin{array}{l}\text { Noncyanotic } \\
(n=84)\end{array}$ & 4 & 4.8 & 22 & 26.2 \\
\hline $\begin{array}{l}\text { Cyanotic } \\
(n=54)\end{array}$ & 4 & 7.4 & 25 & 46.3 \\
\hline
\end{tabular}

${ }^{*} p>0.10$ (Fisher's exact test).

$t p<0.05$ (Fisher's exact test).

inadequate myocardial protection). Five deaths occurred as a result of suboptimal anatomic or physiologic correction. The mean age for survivors was 32.7 months (95\% CL 24.7 to 40.7 months) compared with a mean age of 9.8 months (95\% CL 2.1 to 17.5 months) for patients who died. This difference in mean ages between those who survived and those who died was statistically significant in bivariate comparison (Student's $t=$ $4.42, d f=39.89, p, 0.001$ ) but not in the multivariate analysis of factors associated with survival. Two patients $(2 / 62=3.2 \%)$ receiving blood cardioplegia died, and six patients $(6 / 76=7.9 \%)$ who received crystalloid cardioplegia died ( $p=0.29$, Fisher's exact test, Table IV). Multiple logistic regression did not find this difference in mortality rate to be significant at the $p<0.05$ level $(p=$ 0.431; Table III). Complications were likewise found by multiple logistic regression to have statistically significant associations only with aortic crossclamp time $(p=0.0004)$ and not with cardioplegia ( $p=0.970$; Table III). Cyanotic patients had a higher incidence of complications than did noncyanotic patients $(p=0.028$, Fisher's exact test, Table IV). The types of complications were fairly typical for this spectrum of patients (Table V).

Inotropic support, ventricular function, and ICU length of stay. Multivariate analysis of variance (Table VI) for postrepair inotropic support, ventric-
Table V. Incidence of postoperative complications and 30-day hospital mortality for 138 patients

\begin{tabular}{lrc}
\hline Complication & $n$ & \% of 138 \\
\hline None & 91 & 66.0 \\
Pulmonary & 14 & 10.1 \\
Arrhythmia & 9 & 6.5 \\
Infectious & 7 & 5.1 \\
Organ failure & 6 & 4.3 \\
Reoperation & 5 & 3.6 \\
Neurologic & 3 & 2.2 \\
Tamponade & 2 & 1.4 \\
Other & 15 & 10.9 \\
Mortality & 8 & 5.8 \\
\hline
\end{tabular}

ular function, and ICU length of stay revealed once again that ischemic time was the most important determinant and that prolonged aortic crossclamp time adversely influenced all measured end points. Younger age was associated with more inotropic support during the operation $(p=0.032)$. Patients requiring urgent surgery had longer ICU stays $(p=$ $0.001)$. Cyanotic patients received more inotropic support after the operation $(p=0.005)$ but otherwise were not demonstrably different with respect to intraoperative inotropic support, echocardiographic findings, or ICU length of stay.

By all statistical analyses, the use of blood cardioplegia failed to have a statistically advantageous association with any of the clinically measured end points. Crystalloid cardioplegia was associated with less inotropic support during the operation but not with better ventricular function when compared with blood cardioplegia (Table VI). The cardioplegic agent used did not have a statistically significant association with any of the other clinical or care process end points.

\section{Discussion}

This study was designed at a time (1994) when integrated blood cardioplegic techniques (i.e., antegrade, retrograde, warm induction, and warm reperfusion) had become associated with improved results in adult patients, and their feasibility in pediatric patients had been demonstrated. ${ }^{5-9} \mathrm{Al}$ though we used integrated blood cardioplegia for adults, like many others we used cold antegrade crystalloid cardioplegia (Plegisol solution) combined with systemic hypothermia for pediatric myocardial protection. Because of occasional experiences with a heart that functioned worse than expected after aortic crossclamping, as well as an awareness of the growing evidence of the superiority 
Table VI. Results of multivariate analysis of variance for inotropic support, ventricular function, and ICU length of stay

\begin{tabular}{|c|c|c|c|c|c|c|c|c|}
\hline \multirow[b]{3}{*}{$\begin{array}{c}\text { Dependent } \\
\text { variables }\end{array}$} & \multicolumn{8}{|c|}{ Determinants (independent variables) } \\
\hline & \multicolumn{2}{|c|}{ Cardioplegia } & \multirow[b]{2}{*}{$\begin{array}{c}\text { Aortic } \\
\text { crossclamp } \\
\text { time } \\
\text { (b) }\end{array}$} & \multirow[b]{2}{*}{$\begin{array}{l}\text { Age } \\
\text { (b) }\end{array}$} & \multicolumn{2}{|c|}{ Urgency } & \multicolumn{2}{|c|}{ Cyanosis } \\
\hline & $\begin{array}{c}\text { Blood: } \\
\text { mean } \\
{[95 \% \text { CL] }}\end{array}$ & $\begin{array}{c}\text { Cryst: } \\
\text { mean } \\
{[95 \% \text { CL] }}\end{array}$ & & & $\begin{array}{c}\text { Elective: } \\
\text { mean } \\
{[95 \%} \\
C L]\end{array}$ & $\begin{array}{c}\text { Urgent: } \\
\text { mean } \\
{[95 \% \mathrm{CL}]}\end{array}$ & $\begin{array}{l}\text { Noncyan: } \\
\text { mean } \\
{[95 \% \mathrm{CL}]}\end{array}$ & $\begin{array}{c}\text { Cyan: } \\
\text { mean } \\
{[95 \% \text { CL] }}\end{array}$ \\
\hline $\begin{array}{l}\text { INT-OR } \\
\qquad(\mu \mathrm{g} / \mathrm{kg} / \mathrm{min})\end{array}$ & $\begin{array}{c}7.45 \\
{[6.0-8.9]}\end{array}$ & $\begin{array}{c}5.15 \S \\
{[4.2-6.1]}\end{array}$ & $0.049 \pi$ & $-0.019 \ddagger$ & $\begin{array}{c}5.76 \\
{[5.0-6.5]}\end{array}$ & $\begin{array}{c}9.04 \dagger \\
{[5.1-13.0]}\end{array}$ & $\begin{array}{c}5.07 \\
{[4.1-6.0]}\end{array}$ & $\begin{array}{c}7.87^{*} \\
{[6.4-9.4]}\end{array}$ \\
\hline $\begin{array}{l}\text { INT-PO } \\
\quad(\mu \mathrm{g} / \mathrm{kg} / \mathrm{min})\end{array}$ & $\begin{array}{c}6.16 \\
{[4.8-7.5]}\end{array}$ & $\begin{array}{c}5.14^{*} \\
{[4.0-6.3]}\end{array}$ & $0.050 \uparrow$ & $-0.009^{*}$ & $\begin{array}{c}5.11 \\
{[4.2-6.0]}\end{array}$ & $\begin{array}{c}8.80^{*} \\
{[5.8-11.8]}\end{array}$ & $\begin{array}{c}4.01 \\
{[3.0-5.0]}\end{array}$ & $\begin{array}{c}7.998 \\
{[6.6-9.4]}\end{array}$ \\
\hline $\begin{array}{l}\text { ECHO-OR } \\
\text { grade } 1-10\end{array}$ & $\begin{array}{c}9.45 \\
{[9.1-9.8]}\end{array}$ & $\begin{array}{c}9.55^{*} \\
{[9.3-9.8]}\end{array}$ & $-0.009 \S$ & $0.001^{*}$ & $\begin{array}{c}9.56 \\
{[9.4-9.8]}\end{array}$ & $\begin{array}{c}9.17^{*} \\
{[8.5-9.8]}\end{array}$ & $\begin{array}{c}9.64 \\
{[9.4-9.9]}\end{array}$ & $\begin{array}{c}9.30^{*} \\
{[9.0-9.6]}\end{array}$ \\
\hline $\begin{array}{l}\text { ECHO-PO } \\
\text { grade } 1-10\end{array}$ & $\begin{array}{c}9.52 \\
{[9.3-9.8]}\end{array}$ & $\begin{array}{c}9.22^{*} \\
{[8.8-9.6]}\end{array}$ & $-0.023 \pi$ & $0.005 \dagger$ & $\begin{array}{c}9.38 \\
{[9.1-9.7]}\end{array}$ & $\begin{array}{c}9.22^{*} \\
{[8.6-9.9]}\end{array}$ & $\begin{array}{c}9.43 \\
{[9.1-9.8]}\end{array}$ & $\begin{array}{c}9.25^{*} \\
{[8.9-9.6]}\end{array}$ \\
\hline ICU days & $\begin{array}{c}7.65 \\
{[5.7-9.6]}\end{array}$ & $\begin{array}{c}7.55^{*} \\
{[5.9-9.2]}\end{array}$ & $0.080 \uparrow$ & $-0.009^{*}$ & $\begin{array}{c}6.53 \\
{[5.4-7.7]}\end{array}$ & $\begin{array}{c}14.729 \\
{[10.1-19.3]}\end{array}$ & $\begin{array}{c}5.64 \\
{[4.4-6.8]}\end{array}$ & $\begin{array}{c}10.55 \dagger \\
{[8.2-12.9]}\end{array}$ \\
\hline
\end{tabular}

Mean, Mean value for each dependent variable (e.g., INT-OR) within subgroups defined by determinants (e.g., blood cardioplegia). $b$, slope by regression analysis; $C L$, confidence limits; Cryst, crystalloid; Cyan, cyanotic; $E C H O$, echocardiographic assessment of ventricular function intraoperatively (OR) and postoperatively $(P O) ; I N T$, total dose of inotropic support intraoperatively and postoperatively. Exact $p$ values are presented in the text. $p$ values were obtained from multivariate analysis of variance for each dependent variable considered individually. Across cardioplegia groups, patients received a grand mean of $6.9 \mu \mathrm{g} / \mathrm{kg} / \mathrm{min}(95 \% \mathrm{CL} 5.34$ to 7.03) intraoperative inotropic support; a grand mean of $6.0 \mu \mathrm{g} / \mathrm{kg} / \mathrm{min}$ (95\% CL 4.74 to 6.46) of inotropic support in the first 8 hours postoperatively. The grand mean grading of intraoperative ventricular function was 9.51 ( $95 \%$ CL 9.32 to 9.70 ), and at 24 hours postoperatively was 9.36 ( $95 \%$ CL 9.11 to 9.61). The grand mean ICU length of stay was 7.59 days (95\% CL 6.37 to 8.82 ).

${ }^{*} p>0.10$.

$\uparrow p>0.05$.

$\$ p<0.05$.

$\S p<0.01$.

$\pi p<0.001$.

of integrated blood cardioplegic techniques in stressed hearts, we felt compelled to evaluate the clinical use of blood cardioplegia for our pediatric patients. ${ }^{10}$ The technical disadvantages of using retrograde and warm blood cardioplegia techniques in some pediatric patients, particularly newborn infants, prompted us to use blood essentially as an additive to our cardioplegic strategy, thus randomizing patients to either Plegisol solution or blood with Plegisol solution. Because some investigators raised questions regarding the optimum systemic perfusate temperature at which aortic crossclamping should occur, we chose a moderately hypothermic temperature for aortic crossclamping $\left(30^{\circ} \mathrm{C}\right) \cdot{ }^{11-13}$

This type of study has important limitations. The differences in myocardial cellular and subcellular functions in neonates, the effects of cyanosis, cardiopulmonary bypass, systemic perfusion temperatures, and of reperfusion, and the varied pathologic entities involved obfuscate cardioplegic effects. ${ }^{14-18}$ Arbitrary decision-making for inotropic support and subjective echocardiographic assessment of ventricular function lessen the validity of the conclusions from these portions of the study. Technical and physiologic challenges are common in complex con- genital heart surgery, and prolonged ischemia or suboptimal physiologic results may overshadow the benefits or differences of cardioplegic agents. Last, arguments abound regarding the benefits of various ion concentrations, for example, calcium, in cardioplegic solutions, and a clinical study of this size cannot possibly adequately address all of these issues. ${ }^{19-22}$

Our study failed to show any statistical advantage for blood cardioplegia, but these results are not surprising inasmuch as good results have been reported with either cold blood or cold crystalloid antegrade cardioplegic techniques in the pediatric age group. ${ }^{9,23,24}$ In fact, in our study the postoperative ventricular function as measured by echocardiographic mean score was quite good for both the blood and crystalloid cardioplegia groups, that is, ECHO-PO 9.52 for blood cardioplegia and 9.22 for crystalloid cardioplegia (scale 1 to 10; Table VI). Our study failed to demonstrate any benefit of blood cardioplegia in cyanotic patients. Despite the equivocal findings of our study, limitations of antegrade cold crystalloid cardioplegia have been previously noted, ${ }^{25,26}$ and the increasing evidence of the benefits of integrated blood cardioplegia, as well as 
recent experimental evidence suggesting the superiority of blood cardioplegia for cyanotic patients, provide compelling reasons for adopting a blood cardioplegic strategy. ${ }^{17 *}$

Perhaps the most important aspect of this study is the recognition that no obvious benefits, if any, can be anticipated by use of a blood cardioplegic strategy in surgery for congenital heart disease when only an antegrade hypothermic dosing technique is used. The integrated cardioplegic approach using warm, cold, antegrade, and retrograde techniques with substrate enhancement has achieved well-deserved popularity in adults and may be beneficial for the pediatric population as well. It is unclear whether this approach is safe in all pediatric patients, particularly neonates, but the technical feasibility of an integrated approach in neonates has been demonstrated. ${ }^{27}$ It is important to note, however, that the efficacy of integrated cardioplegic techniques has not been demonstrated clinically in neonates or young infants.

Because of its demonstrated superiority in adults and infant animal studies, we currently attempt to use an integrated blood cardioplegic regimen in as many pediatric patients as possible, for example, using antegrade cold blood cardioplegia for operations in neonates and younger infants with warm cardioplegic reperfusion at the end of the ischemic period and before aortic unclamping. In older children, it is easy to use a fully integrated system incorporating warm substrate-enriched antegrade and retrograde techniques at the initiation and conclusion of the ischemic period with intermittent cold blood cardioplegia during the remainder of the ischemic arrest. Crystalloid cardioplegia is currently reserved for patients with anticipated brief ischemic times and in whom the use of blood cardioplegia might require addition of blood to the priming circuit (e.g., atrial septal defects in the older child).

Further elucidation of myocyte ion fluxes, subcellular apparatus mechanisms, and coronary endothelial processes will undoubtedly improve our understanding and alter our myocardial protective strategies for both pediatric and adult populations. The potential benefits that may be derived from various substrate enhancements, preconditioning

*Bolling K, Allen B, Rahman S, Wang T, Kronon M, Feinberg H. The superiority of blood versus crystalloid cardioplegia in neonatal myocardial protection. Presented at the Twentysecond Annual Meeting of The Western Thoracic Surgical Association, June 26-29, 1996. agents, or hyperpolarizing substances remain to be demonstrated. ${ }^{28,29}$ Because of the major effect of aortic crossclamp time (ischemic time) on clinical results, we must continue to look to experimental animal models and investigations to help clarify these issues.

\section{REFERENCES}

1. Follette DM, Mulder DG, Maloney JV, Buckberg GD. Advantages of blood cardioplegia over continuous coronary perfusion or intermittent ischemia: experimental and clinical study. J Thorac Cardiovasc Surg 1978;78:604-19.

2. Robinson LA, Schwartz GD, Goddard DB, Fleming WH, Galbraith TA. Myocardial protection for acquired heart disease surgery: results of a national survey. Ann Thorac Surg 1995;59:361-72.

3. Bilfinger TV, Moeller JT, Kurusz M, Grimson RC, Anagnostopoulos CE. Pediatric myocardial protection in the United States: a survey of current clinical practice. Thorac Cardiovasc Surg (Stuttgart) 1992;40:214-8.

4. Young JN, Choy IO. Aortic root pressure monitoring during antegrade cardioplegia administration. Ann Thorac Surg 1996;62:1213-4.

5. Buckberg GD. Antegrade/retrograde blood cardioplegia to ensure cardioplegic distribution: operative techniques and objectives. J Card Surg 1989;4:216-38.

6. Buckberg GD, Beyersdorf F, Allen BS, Robertson JM. Integrated myocardial management: background and initial application. J Card Surg 1995;10:68-89.

7. Loop FD. Crystalloid versus blood cardioplegia. Semin Thorac Cardiovasc Surg 1993;5:122-4.

8. Iverson LI, Young JN, Ennix CL, Ecker RR, Moretti RL, Lee J, et al. Myocardial protection: a comparison of cold blood and cold crystalloid cardioplegia. J Thorac Cardiovasc Surg 1984;87:509-16.

9. Drinkwater DC, Cushen CK, Laks H, Buckberg GD. The use of combined antegrade-retrograde infusion of blood cardioplegic solution in pediatric patients undergoing heart operations. J Thorac Cardiovasc Surg 1992;104:1349-55.

10. Beyersdorf F, Buckberg GD. Myocardial protection in patients with acute myocardial infarction and cardiogenic shock. Semin Thorac Cardiovasc Surg 1993;5:151-61.

11. Williams WG, Rebeyka IM, Tibshirani RJ, Coles JC, Lightfoot NE, Mehra A, et al. Warm induction blood cardioplegia in the infant: a technique to avoid rapid cooling myocardial contracture. J Thorac Cardiovasc Surg 1990;100:896-901.

12. Buckberg GD. Myocardial temperature management during aortic clamping for cardiac surgery: protection, preoccupation, and perspective. J Thorac Cardiovasc Surg 1991;102: 895-903.

13. Kempsford RD, Hearse DJ. Protection of the immature heart: temperature-dependent beneficial or detrimental effects of multidose crystalloid cardioplegia in the neonatal rabbit heart. J Thorac Cardiovasc Surg 1990;99:269-79.

14. Kato $H$, Galiñanes $M$, Elliot MJ, de Leval MR, Hearse DJ. Comparison of single- and multi-dose crystalloid cardioplegia to protect the immature myocardium. Eur J Cardiothorac Surg 1994;8:645-50.

15. Blatchford JW, Barragry TP, Lillehei TJ, Ring WS. Effects of cardioplegic arrest on left ventricular systolic and diastolic 
function of the intact neonatal heart. J Thorac Cardiovasc Surg 1994;107:527-35.

16. Jessen ME, Abd-Elfattah AS, Wechsler AS. Neonatal myocardial oxygen consumption during ventricular fibrillation, hypothermia, and potassium arrest. Ann Thorac Surg 1996; 61:82-7.

17. Corno AF, Bethencourt DM, Laks H, Haas GS, Bhuta S, Davtyan HG, et al. Myocardial protection in the neonatal heart: a comparison of topical hypothermia and crystalloid and blood cardioplegic solutions. J Thorac Cardiovasc Surg 1987;93:163-72.

18. Morita K, Ihnken K, Buckberg GD. Studies of hypoxemic/ reoxygenation injury: with aortic clamping. XII. Delay of cardiac reoxygenation damage in the presence of cyanosis: a new concept of controlled cardiac reoxygenation. J Thorac Cardiovasc Surg 1995;110:1265-73.

19. Bolling K, Kronon M, Allen BS, Ramon S, Wang T, Hartz R, et al. Myocardial protection in normal and hypoxically stressed neonatal hearts: the superiority of hypocalcemic versus normocalcemic blood cardioplegia. J Thorac Cardiovasc Surg 1996;112:1193-201.

20. Pearl JM, Laks H, Drinkwater DC, Meneshian A, Sun B, Gates R, et al. Normocalcemic blood or crystalloid cardioplegia provides better neonatal myocardial protection than does low-calcium cardioplegia. $\mathbf{J}$ Thorac Cardiovasc Surg 1993;105:201-6.

21. Baker EJ, Olinger GN, Baker JE. Calcium content of St. Thomas' II cardioplegic solution damages ischemic immature myocardium. Ann Thorac Surg 1991;52:993-9.

22. Meldrum DR, Cleveland JC, Sheridan BC, Rowland RT, Banerjee A, Harken AH. Cardiac surgical implication of calcium dyshomeostasis in the heart. Ann Thorac Surg 1996;61:1273-80.

23. Kirklin JK, Blackstone EH, Kirklin JW, McKay R, Pacifico $\mathrm{AD}$, Bargeron LM. Intracardiac surgery in infants under age 3 months: incremental risk factors for hospital mortality. Am J Cardiol 1981;48:500-6,

24. Planché C, Bruniaux J, Lacour-Gayet F, Kachaner J, Binet J, Sidi D. Switch operation for transposition of the great arteries in neonates. J Thorac Cardiovase Surg 1988;96:35463.

25. Bull C, Cooper J, Stark J. Cardioplegic protection of the child's heart. J Thorac Cardiovase Surg 1984;88:287-93.

26. del Nido PJ, Mickle DA, Wilson GJ, Benson LN, Weisel RD, Coles JC, et al. Inadequate myocardial protection with cold cardioplegic arrest during repair of tetralogy of Fallot. J Thorac Cardiovasc Surg 1988;95:223-9.

28. Yonenaga K, Yasui H, Kado H, Nakamura Y, Shiokawa $Y$, Yamamoto $T$, et al. Myocardial protection by retrograde cardioplegia in arterial switch operation. Ann Thorac Surg 1990;50:238-42.

29. Cleveland JC, Meldrum DR, Rowland RT, Banerjee A, Harken A. Optimal myocardial preservation: cooling, cardioplegia, and conditioning. Ann Thorac Surg 1996;61:760-8.

30. Buckberg GD. Update on current techniques of myocardial protection. Ann Thorac Surg 1995;60:805-14.

\section{Discussion}

Dr. Bradley S. Allen (Chicago, Ill.). Although numerous investigators have demonstrated the superiority of blood over crystalloid cardioplegia in the mature heart, few have examined this question in the immature heart. In view of the structural, functional, and metabolic differences, extrapolation of adult cardioplegic strategies to the infant may not be valid. This study seems to demonstrate no difference between blood and crystalloid cardioplegia. However, unlike experimental studies in which the preoperative state and operative procedure are identical, these variables are often very different between patients, making the data difficult to interpret.

I have several questions for the authors. The composition of Plegisol solution is based on numerous studies that determined the optimal level for each component when used as a crystalloid solution. Likewise, the ideal composition of blood cardioplegia was determined by a similar process. In other words, blood cardioplegia is more than just adding blood to Plegisol solution, because the resulting solution has not been specifically formulated to optimize myocardial protection. Do the authors believe that this could have affected their results, and do they have any experience with some of the more conventional blood cardioplegic solutions?

Second, inasmuch as the pediatric heart may be more tolerant to ischemia, it is not surprising that there is no difference between blood and crystalloid cardioplegia in normal hearts with relatively short crossclamp times. Although the authors excluded simple atrial septal defects for this reason, $50 \%$ of their patients had ventricular septal defects or uncomplicated aortic stenosis. These children should do well no matter what the method of myocardial protection. Therefore, was there a difference between blood and crystalloid cardioplegia in patients undergoing more complex procedures requiring longer crossclamp times, especially since crossclamp time was a predictor of a bad outcome?

The morbidity and mortality in cyanotic infants were increased, supporting other reports which document that these infants are less tolerant to ischemia and therefore more dependent on the method of myocardial protection. In a recent experimental study, we demonstrated that in hypoxic hearts blood cardioplegia provides substantially better myocardial protection than does crystalloid cardioplegia. Do the authors know whether there was any difference between blood and crystalloid cardioplegia when only the cyanotic patients were compared?

We recently found that myocardial protection is markedly improved in neonatal hearts when the cardioplegic solution is delivered at a pressure less than $50 \mathrm{~mm} \mathrm{Hg}$. Inasmuch as you measured the cardioplegic infusion pressure, could you tell us what it was in each group and whether it differed between groups?

Finally, the two cardioplegic solutions were delivered according to identical protocols. Although using similar delivery strategies reduces variability in the study, it does not allow each solution to be used to its maximal potential. For instance, using a warm reperfusion or "hot shot" before aortic unclamping has previously been shown to improve myocardial protection with blood cardioplegia in adults. We have recently demonstrated this to be true as well in neonates. Since a warm reperfusate would probably be deleterious if delivered via a crystalloid solution, it is never used when identical protocols are followed. However, if this modality is not incorporated, blood cardioplegia is not used to its maximal potential. There- 
fore the question of which solution is better cannot be determined. Since the authors state that they now use a warm reperfusate in most pediatric patients, could they comment on whether they think incorporating this strategy would have changed their results?

This is an important paper. Only from studies such as this will we be able to determine the optimal method of protection in infants, instead of adopting strategies determined in the adult.

Dr. Young. Dr. Allen, thank you for your comments and questions. You asked five questions, and I will combine my answers.

The first and the fifth questions concerned the components of the cardioplegic agent and the different techniques. We designed this study in 1994 when we were routinely using antegrade blood cardioplegic techniques in our adult patients but using just cold crystalloid cardioplegia in our pediatric patients. I was reluctant to move too far too fast, because we thought that the results with the crystalloid solution were good. Additionally, the technical issues of using a retrograde technique in newborn infants can be problematic; therefore we elected to use only antegrade cold agents. We have had some experience now, as I know you have, with retrograde techniques in older children. We do not use them very much yet in newborn infants, but certainly in older children it is fairly easy to use an antegrade blood cardioplegic technique with warm induction, cold maintenance, hot shot, and substrate reperfusions. However, I do not have any data to report to you from that experience.

I agree that it is an oversimplification to suggest that adding blood to Plegisol solution creates an additive situation. Obviously this is a topic for a long discussion concerning which agents should be used. I know you and your group have done extensive work in this area. However, we were using Plegisol solution plus blood in our adult population; we were happy with those results, and we thought that was a logical first step, because there were no large differences between the two agents.

We found no difference at all among the cyanotic patients between the two cardioplegia groups. We measure pressures routinely in the aortic root when administering cardioplegia. I think it is important to do so, particularly in the younger infant and smaller child, because damage can occur if pressure is not accurately measured, as has been demonstrated by several studies. However, we did not address pressure differences per se as one of the determinants in this population.

Appendix. Constituents of Plegisol solution and blood cardioplegic solution

\begin{tabular}{ll}
\hline \multicolumn{1}{c}{ Plegisol } & \multicolumn{1}{c}{ Blood cardioplegia } \\
\hline $\mathrm{Na}^{+} 120 \mathrm{mEq} / \mathrm{L}$ & Blood/Plegisol = 4:1 \\
$\mathrm{K}^{+} 16 \mathrm{mEq} / \mathrm{L}$ & $\mathrm{K}^{+}=15 \mathrm{mEq} / \mathrm{L}$ \\
$\mathrm{Mg}^{++} 32 \mathrm{mEq} / \mathrm{L}$ & \\
$\mathrm{Ca}^{++} 2.4 \mathrm{mEq} / \mathrm{L}$ & \\
$\mathrm{HCO}_{3}^{-} 10 \mathrm{mEq} / \mathrm{L}$ & \\
$\mathrm{Cl}^{-} 160 \mathrm{mEq} / \mathrm{L}$ & \\
$\mathrm{pH} 7.8 \mathrm{mEq} / \mathrm{L}$ & \\
\hline
\end{tabular}

